\title{
P04-4I. Kinetics of antibody neutralization and viral evolution following envelope vaccination in SIV-infected rhesus monkeys
} A Basavapathruni*, W Yeh, R Coffey, J Whitney, P Hraber, A Giri, S Rao, J Mascola, G Nabel, B Korber, M Seaman and N Letvin

Address: Viral Pathogenesis, Beth Israel Deaconess Medical Center/Harvard Medical School, Boston, MA, USA

* Corresponding author

from AIDS Vaccine 2009

Paris, France. 19-22 October 2009

Published: 22 October 2009

Retrovirology 2009, 6(Suppl 3):P69 doi:10.1 I86/1742-4690-6-S3-P69

This abstract is available from: http://www.retrovirology.com/content/6/S3/P69

(c) 2009 Basavapathruni et al; licensee BioMed Central Ltd.

\section{Background}

While neutralizing antibodies should limit the replication of HIV/SIV in the infected individual, autologous neutralizing antibodies are generated too late following HIV/SIV infection to contribute to early virus control. The present study addresses whether vaccine-induced immune responses accelerate the generation of autologous neutralizing antibodies following SIV challenge in rhesus monkeys, and if this antibody response shapes viral sequence evolution.

\section{Methods}

Two groups of six monkeys were vaccinated with a plasmid DNA prime/recombinant adenovirus serotype 5 boost regimen of either gag/pol or env/gag/pol immunogens and subsequently challenged with SIVmac251. Fulllength envelope from plasma virus was sequenced by single genome amplification to identify sites of envelope mutations. The rate of the generation of an autologous neutralizing antibody response, and the impact of envelope mutations on escape from antibody neutralization were evaluated using a luciferase reporter gene-based neutralization assay.

\section{Results}

The gag/pol vaccinated monkeys developed autologous neutralizing antibody responses by 18 weeks post-challenge, while the env/gag/pol vaccinated monkeys developed this response as early as 7 weeks post-challenge. Moreover, this antibody response in the env/gag/pol-vac- cinated group conferred immune pressure on the virus. Phylogenetic analysis of envelope sequences illustrated that env vaccination was associated with an increased accumulation of mutations. Prevalent mutations in sequences from gag/pol vaccinees included deletions in both variable loops $1(\mathrm{~V} 1)$ and 4 , whereas deletions in the env-vaccinees occurred only in V1. A pseudovirion expressing a V1 loop deletion and accompanying point mutations conferred delayed neutralization and escape to sera from env-vaccinees. These findings suggest that env vaccination elicited neutralizing antibodies focused on V1.

\section{Conclusion}

Our results indicate that env vaccination is associated with an accelerated development of autologous neutralizing antibodies. These antibodies were focused at least in part on the V1 region of Env, since there was selective pressure in this region of the envelope for the evolution of mutational changes. 